\title{
Pengembangan Metode Desain Logo dan Sistem Grafis untuk Mendukung Pembelajaran Desain Komunikasi Visual
}

\author{
Sayatman, Nurina Orta Darmawati, dan Putri Dwitasari \\ Departemen Desain Produk Industri, Fakultas Arsitektur Desain dan Perencanaan, \\ Institut Teknologi Sepuluh Nopember \\ Email: sayatasik@prodes.its.ac.id
}

\begin{abstract}
Abstrak - Logo secara prinsip adalah simbol khusus dan khas yang mewakili suatu entitas dan bahkan dapat menjadi bagian dari properti legal entitas tersebut. Sebagai bagian dari identitas visual, sebuah logo juga dapat berfungsi sebagai sarana membangun brand entitasnya.Oleh karena itu dalam kurikulum pendidikan Desain Komunikasi Visual, perancangan identitas visualtermasuk logo dansistem grafisnya menjadi bagian yang mendasar untuk dipelajari. Tantangannya adalah bagaimana mahasiswa mampu membuat konsep logo dan identitas visualsecara terintegrasi sebagai solusi untuk menjawab permasalahan desain yang dibutuhkan.Melalui pengembangan metode pembelajaran desain logo dan sistem grafis yang simpel dan sistematis ini diharapkan dapat membantu mahasiswamerancang logo secara lebih mudah tahap demi tahap. Pemahaman terhadapprinsipprinsip dasar desain logo, analisa sampai menghasilkan konsep desain menjadi penting dalam proses pembelajaran. Sehingga pada akhirnya mahasiswa mampu menghasilkan konsepdan implementasi desain logo yang kuat sebagai sebuah sistem identitas visual (visualidentity system)yang terintegrasi dan komprehensif.
\end{abstract}

Kata kunci: logo, identitas visual, sistem grafis

Abstract-The logo in principle is a special and distinctive symbol that represents an entity and may even be part of the legal property of that entity. As part of the visual identity, a logo can also serve as a means of building its entity brand. Therefore, in the curriculum of Visual Communication Design education, the design of visual identities including logos and graphical systems become a fundamental part to learn. The challenge is how students are able to create the concept of logo and visual identity are integrated as a solution to answer the required design issues. Through the development of learning method of logo design and graphic system that is simple and systematic is expected to help students design the logo more easily step by step. Understanding of the basic principles of logo design, analysis to produce design concepts becomes important in the learning process. So in the end students are able to produce the concept and implementation of a strong logo design as a system of visual identity is integrated and comprehensive.

Keywords: logo, visual identity, graphics system

\section{PENDAHULUAN}

Logo sebagai salah satu ciri visual sebuah entitas berfungsi sebagai sarana identifikasi, diferensiasi dan bahkan dapat menjadi bagian dari properti legal entitas tersebut. Penggunaan logo dan identitas visual sering kita lihat dalam kehidupan sehari-hari di sekitar kita. Misalnya sebuah perusahaan, lembaga, institusi, partai politik hampir semua memiliki logo sebagai identitas visual entitasnya. Bahkan hampir semua produk yang kita jumpai sudah jamak menggunakan logo danpenciri visual lainnya. Ini membuktikan bahwa disiplin ilmu desain komunikasi visual, khususnya logo dan identitas visual banyak dibutuhkan dalam kehidupan masyarakat [1, 2, 3, 4 dan 5].

Sebuah logo biasanya dibentuk oleh unsur-unsur visual seperti tipografi (letter mark), gambar (picture mark), warna identitas (color identity), tata letak (layout)atau hasil kombinasinya [6]. Elemen-elemen tersebut kemudian dirancang secara padu agar memenuhi fungsi komunikasi maupun fungsi estetiknya.Diperlukan kreativitas dan pemahaman yang komprehensif untuk mendesain logo dengan baik. Oleh karenanya perlu dikembangkan metode yang tepat agar mahasiswa lebih mudah memahami prinsip-prinsip mendesain logo yang efektif sehingga mereka mampu merancang konsepdan implementasi logoserta sistem identitas visualsecara terintegrasi dalam berbagai media sebagai sebuah design system.

Hasil dari pengembangan metode ini diharapkan:

1) Mahasiswa memiliki pengetahuan tentang prinsip-prinsip perancangan logo dan identitas visual (visual identity) dan system grafis (graphic system).

2) Mampu membuat konsep desain yang relevan sebagai solusi dari permasalahan desain yang dibutuhkan sesuai tuntutan brief/TOR.

3) Mampu mewujudkannya dalam bentuk desain logo dan visualidentity system sesuai dengan corporate programnya.

4) Mampu membuat desain aplikasi dalam bentuk prototype, mockuplengkap sesuai format presentasi yang ditentukan.

5) Hasil penelitian ini juga dapat dimanfaatkan sebagai bahan kajian mahasiswa yang berminat mendalami peminatan pada system identitas visual dan branding corporate.

\section{METODE PENELITIAN}

A. Tahappengambilan data

a. Studi pendahuluan

Studi pendahuluan dilakukan pada hasil penelitian bahan ajar pada mata kuliah Desain Komunikasi Visual Identitas [7 dan 8].Berdasar pada hasil penelitian tersebut, dengan disertai evaluasi pada proses perkuliahan studio desain komunikasi visual, maka diperoleh gambaran problem untuk kemudian dilakukan perbaikan dan pengembangan metodenya.

b. Studi pustaka 
Studi pustaka dari berbagai sumber terkait landasan teori yang mendukung metode desain logo dan system identitas visual (visual identity system) atau system grafis (graphic system).Studi referensi dilakukan terhadap berbagai contoh desain dan implementasi identitas visual logo dan system grafisnya.

c. Benchmarking

Benchmarking dilakukan ke beberapa komparator yang dianggap berhasil menerapkan konsep system identitas yang relevan sehingga menghasilkan bahan studi yang cukup komprehensif untuk contoh implementasi desain logo dan visual identity system.

\section{$B$. Tahapanalisa dan pengembangan metode}

Tahapanstudidananalisameliputistruktur pembelajaran studio perancangan logo dan sistem grafis disusun melalui tahapantahapan proses desain sebagai berikut:

Tahap 1: Introduction/Project Overview

Tahap 2: Identification, Research of Information \& Analysis

Tahap 3: Design Concept

Tahap 4: Exploration/Development and Refinement.

Tahap 5: Production/Evaluation

\section{Tahap evaluasi}

Bertujuan untuk mengevaluasi semua proses dalam setiap tahapnya, sehingga dapat diperoleh masukan-masukan dan umpan balik (feedback) untuk perbaikan-perbaikan di tahap berikutnya.Alur proses penelitian dapat dilihat pada Gambar 1.

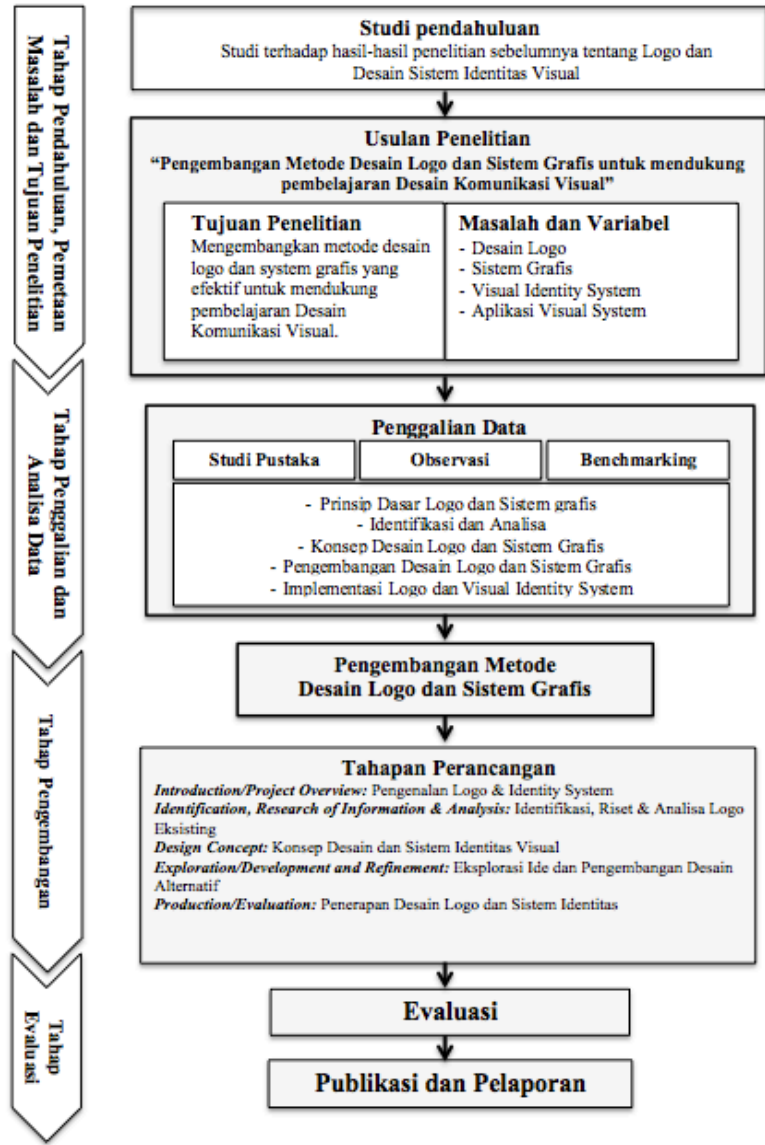

Gambar 1. Alur proses dan tahapan penelitian

\section{HASILDANPEMBAHASAN}

A. Konsep perancangan

Dalam penelitian terdahulu, peneliti dan tim pernah merancang sebuah strategi pembelajaran desain logo dan identitas visual sebagai bagian dari eksperimen model kuliah studio perancangan Desain Komunikasi Visual. Namun demikian perlu dilakukan pengembangan dalam hal metodenya sehingga materi kuliah dapat mudah dipahami baik. Untuk itu perlu disusun struktur pembelajaran yang sistematis melalui tahapan-tahapan proses desain yang komprehensif sebagai berikut:

1. Project overview : Tujuan utama dari tahap ini agar mahasiswa mampu memahami prinsip-prinsip perancangan logo dan visual identity system serta contoh implementasinya dalam berbagai media desain komunikasi visual.

2. Problem identification, research of information \&analysis : Tujuan utama dari tahap ini agar mahasiswa dapat mengidentifikasi dan menyajikan data yang relevan dengan topik bahasan. Kemudian melakukan proses analisa-sintesa dan simpulan yang selanjutnya dapat dijadikan entry point pemecahan masalah desain.

3. Design concept : Tujuan utama dari tahap ini agar mahasiswa mampu merumuskan konsep dan strategi untuk menjawab kebutuhan desain visual identity system yang dibutuhkan customer. Desain konsep yang diminta antara lain; konsep perencanaan, strategi, kriteria desain dan rencana aplikasinya.

4. Exploration/development and refinement: Tujuan utama dari tahap ini agar mahasiswa mampu membuat, mengembangkan dan menyempurnakan gagasan desain visual identity dan graphic system sesuai dengan prinsip-prinsip desain. Kemudian membuat aplikasi desainnyadalam berbagai media secara terintegrasi sesuai dengan corporate program yang ditetapkan.

5. Production/evaluation: Tujuan utama dari tahap ini agar mahasiswa mampu membuat desain logo dan visual identity system dalam bentuk prototype, mock-up atau model 3 dimensi lengkap sesuai format presentasi yang ditetapkan.

Beberapa model/strategi pembelajaran studio DKV Identitas yang dikembangkan, antara lain:

1) Kuliah Pengantar/Overview, bertujuan memberikan wawasan dan gambaran tentang tujuan, manfaat dan ruang lingkup pembelajaran serta tugas yang akan diberikan. Melalui contohcontoh yang diberikan diharapkan mahasiswa lebih memahami topik/materi desain yang diberikan.

2) Tugas/Latihan, bertujuan untuk melihat sejauh mana pemahaman mahasiswa pada materi, diberikan tugas-tugas yang kurang lebih merupakan representasi daya serap mahasiswa pada materi yang diberikan. Tugas yang diberikan berupa teori dan praktek.

3) Presentasi, bertujuan untuk melatih kemampuan mahasiswa dalam menyajikan gagasannya melalui sebuah presentasi yang direncanakannya sebagai bentuk pertanggungjawaban dari karya desain yang dibuatnya.

4) Diskusi, sebagai sarana untuk membiasakan mahasiswa dalam suasana tukar pendapat dalam forum atau group terkait dengan topik yang sedang dibahas.

Keterampilan dasar yang harus dimiliki oleh mahasiswa antara lain:

1. Pengetahuan (key knowledge):

- Memahami prinsip-prinsip desain visual

- Memiliki pengetahuan dasar tentang media dan elemen desain

- Memahami metode menggambar ilustrasi dan gambar bentuk

2. Keterampilan (key skill):

- Menguasai beberapa teknik gambar bentuk dan ilustrasi

- Mampu mengoperasikan komputer grafis

- Mampu menerapkan prinsip-prinsip dan elemen-elemen desain

Agar proses belajar desain logo dan sistem grafis lebih komprehensif, mahasiswa sudah dapat menggunakan teknologi pendukung seperti; komputer grafis, digital camera, scanner atau printer sebagai alat bantu mewujudkan ide-idenya. Mereka juga dapat memanfaatkan alat bantu software desain grafis dalam 
menyelesaikan tugas-tugas perancangannya.

\section{Rancangan metode pembelajaran}

Tabel 1 menunjukkan pengembangan metode pembelajaran yang dirancang untuk perkuliahan studio desain logo dan system grafis.

Tabel 1.Metode pembelajaran desain logo dan sistem grafis

\begin{tabular}{|c|c|c|}
\hline Tax. Bloom & Materi & Capalan Pembelajaran \\
\hline $\begin{array}{c}\text { Knowledg, } \\
\text { Comprehension }\end{array}$ & $\begin{array}{l}\text { Pengenalan Logo } \\
\text { \& Identity System }\end{array}$ & $\begin{array}{l}\text { 1. Memahami pengertian dasar logo dan visual } \\
\text { identity system } \\
\text { 2. Memahami fungsi dan peranan logo } \\
\text { 3. Memahami sejarah perkembangan logo } \\
\text { 4. Memahami trend logo dari masa ke masa }\end{array}$ \\
\hline Analizing & $\begin{array}{l}\text { Identifikasi, Riset } \\
\text { \& Analisa Logo } \\
\text { Eksisting }\end{array}$ & $\begin{array}{l}\text { 1. Memahami Anatomi logo } \\
\text { 2. Mampu mengklasifikasi logo menurut bentuk } \\
\text { 3. Mampu mengklasifikisasi tipe dan jenis logo } \\
\text { 4. Mampu melakukan analisa sintesa data dari } \\
\text { beberapa contoh logo eksisting }\end{array}$ \\
\hline Applying & $\begin{array}{l}\text { Konsep Desain } \\
\text { Logo dan Sistem } \\
\text { Identitas Visual }\end{array}$ & $\begin{array}{l}\text { 1. Mampu merumuskan kriteria desain logo dan } \\
\text { system identitas visual yang dibutuhkan. } \\
\text { 2. Mampu membuat konsep dan strategi visual } \\
\text { desain logo dan system identitas sebagai } \\
\text { solusi permasalahan desain. } \\
\text { 3. Mampu membuat konsep aplikasi desain logo } \\
\text { dan system identitas visual secara terintegrasi } \\
\text { dalam berbagai media. }\end{array}$ \\
\hline $\begin{array}{l}\text { Syntezing, } \\
\text { Creating }\end{array}$ & $\begin{array}{l}\text { Eksplorasi Ide dan } \\
\text { Pengembangan } \\
\text { Desain }\end{array}$ & $\begin{array}{l}\text { 1. Memahami prinsip-prinsip merancang logo } \\
\text { 2. Mampu membuat Sketsa ide (Sketch ide) } \\
\text { 3. Mampu mengembangkan desain alternative } \\
\text { (Alternative Design) } \\
\text { 4. Mampu melakukan penyempurmaan } \\
\text { (Refinement) } \\
\text { 5. Mampu membuat Desain Akhir (Final Design) }\end{array}$ \\
\hline $\begin{array}{l}\text { Syntezing, } \\
\text { Creating }\end{array}$ & $\begin{array}{l}\text { Penerapan Desain } \\
\text { Logo dan Sistem } \\
\text { Identitas }\end{array}$ & $\begin{array}{l}\text { 1. Mampu membuat Guide Line Logo atau } \\
\text { Graphic Standar Manual (GSM). } \\
\text { 2. Mampu mendesain penerapan system identitas } \\
\text { visual pada berbagai media secara terintegrasi. } \\
\text { 3. Mampu membuat presentasi akhir penerapan } \\
\text { system identitas visual, baik dalam bentuk } \\
\text { Mock up, model atau prototype. }\end{array}$ \\
\hline Evaluating & $\begin{array}{l}\text { Penilaian melalui } \\
\text { Presentasi, } \\
\text { Pameran }\end{array}$ & $\begin{array}{l}\text { 1. Mampu menyajikan gagasannya melalui } \\
\text { sebuah presentasi yang direncanakannya } \\
\text { sendiri sebagai bentuk pertanggungjawaban } \\
\text { dari karya desain yang dibuatnya. }\end{array}$ \\
\hline
\end{tabular}

Pemetaan topik desain logo dan sistem grafis

Tabel 2 adalah outline topik, pokok bahasan dan sub pokok bahasan desain logo dan sistem grafis yang akan dikembangkan sebagai materi pembelajaran DKV Identitas.

Tabel 2. Topik bahasan desain logo dan sistem grafis

\begin{tabular}{|c|c|c|}
\hline Unit & Pokok Bahasan & Sub Pokok Bahasan \\
\hline I & $\begin{array}{l}\text { Pengenalan Logo \& } \\
\text { Identity System }\end{array}$ & $\begin{array}{l}\text { a. Pengertian Logo/Visual Identity } \\
\text { b. Fungsi Logo dan identitas visual } \\
\text { c. Sejarah Logo } \\
\text { d. Trend Logo }\end{array}$ \\
\hline II & $\begin{array}{l}\text { Identifikasi, Riset \& } \\
\text { Analisa Logo } \\
\text { Eksisting }\end{array}$ & $\begin{array}{l}\text { a. Anatomi Logo } \\
\text { b. Klasifikasi bentuk Logo } \\
\text { c. Nama/merek } \\
\text { d. Jenis dan type logo } \\
\text { c. Tugas: Klasifikasi dan Analisa Logo }\end{array}$ \\
\hline III & $\begin{array}{l}\text { Konsep Desain Logo } \\
\text { dan Sistem Identitas } \\
\text { Visual }\end{array}$ & $\begin{array}{l}\text { a. Kriteria Logo } \\
\text { b. Konsep Logo dan Identitas Visual } \\
\text { (Concept) } \\
\text { c. Strategi (Strategy) } \\
\text { d. Perencanaan Media (Media } \\
\text { implementation planning) } \\
\text { c. Tugas: Membuat Konsep Desain Logo }\end{array}$ \\
\hline IV & $\begin{array}{l}\text { Eksplorasi Ide dan } \\
\text { Pengembangan } \\
\text { Desain }\end{array}$ & $\begin{array}{l}\text { a. Metode pengembangan ide } \\
\text { b. Exsplorasi Ide Visual } \\
\text { c. Proses Desain Logo } \\
\text { d. Tugas: Eksplorasi desain visual loga. } \\
\text { - Sketsa ide (Sketch idea) } \\
\text { - Desain alternative (Alternative } \\
\text { Design) } \\
\text { - Penyempurnaan (Refinement) } \\
\text { - Desain Akhir (Final Design) }\end{array}$ \\
\hline $\mathbf{v}$ & $\begin{array}{l}\text { Penerapan Desain } \\
\text { Logo dan Sistem } \\
\text { Identitas }\end{array}$ & $\begin{array}{l}\text { b. Pedoman Aplikasi Sistem Identitas } \\
\text { c. Penerapan Desain Identitas } \\
\text { d. Tugas: Pembuatan Presentasi Akhir } \\
\text { (Final presentation) } \\
\text { - Graphic Standar Manual } \\
\text { - Mock up/ Dummy } \\
\text { - Portofolio } \\
\text { c. Evaluasi }\end{array}$ \\
\hline
\end{tabular}

Tahap 1 : Pengantar logo \&identitas visual

Bagian ini merupakan mukadimah dari subjek perancangan tentang logo dan system identitas visual. Pokok bahasan/materi yang diberikan pada tahap pertama ini lebih menekankan pada pemahaman dasar tentang logo, identitas visual dan visual identity system. Sub-sub pokok bahasan yang diajarkan antara lain meliputi: pemahaman tentang definisi dan istilah seputar desain logo dan identitas visual, hal ihwal logo serta fungsi dan trend logo. Metode perkuliahan pada bagian pertama ini disampaikan dalam bentuk kuliah pengantar/teori dan pembahasan contoh-contoh eksisting. Kemudian dilanjutkan dengan diskusi seputar logo dan visual identity system serta penerapannya dalam kehidupan sehari-hari.

Tujuan pembelajaran dari pokok bahasan unit-1 ini adalah:

1. Memberikan pemahaman kepada wahasiswa tentang definisi, fungsi dan peran logo dan identitas visual (visual identity) serta contoh implementasinya.

2. Mahasiswa memahami sejarah perkembangan logo dan trend logo dan visual identity system serta contoh penerapannya dalam desain komunikasi visual.

Gambar 2dan Gambar 3 adalah salahsatu ilustrasi untuk memperkenalkan contoh penerapan logo dan identitas visual dari Information Services Department Hong Kong Brand Guide(2003)dalam Program Branding Hong Kong ”Asia’s Word City".

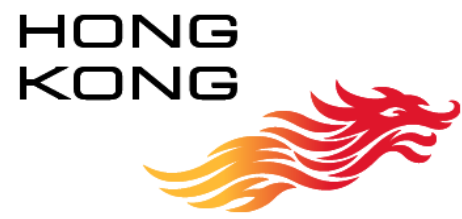

Gambar 2. Logo Hong Kong dengan positioning"Asia's World City"

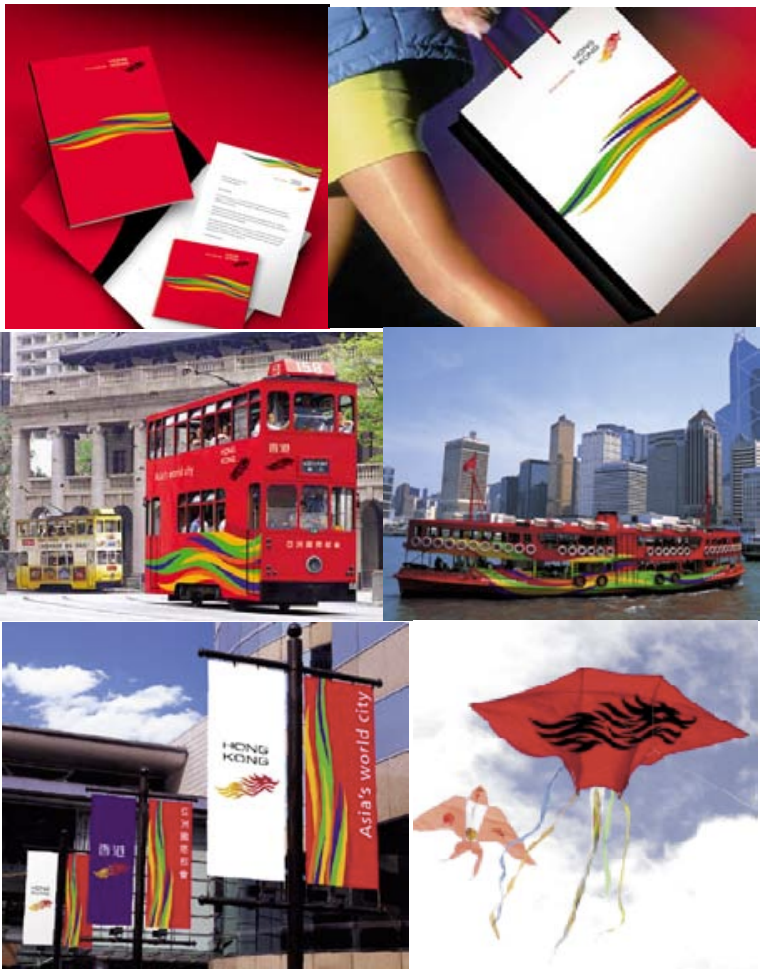

Gambar3. Contoh aplikasi identity system pada Program Branding Hong Kong "Asia's Word City 
Tahap 2 : Identifikasi dan analisa logo eksisting

Merupakan tahap identifikasi, riset informasi dan analisa. Sebelum melakukan proses perancangan, mahasiswa diwajibkan untuk mengidentifikasi dan menganalisa terlebih dahulu contoh-contoh kasus logo eksisting, agar dapat memahami lebih jauh tentang objek yang akan dirancangnya. Ruang lingkup studinya melingkupi beberapa tahap, antara lain: identifikasi masalah, studi eksisting dan analisa logo eksisting. Teori penunjang pembelajaran diberikan untuk membekali mahasiswa dalam proses identifikasi dan analisa logo, antara lain: anatomi logo, klasifikasi logo, jenis dan type logo (Gambar 4).

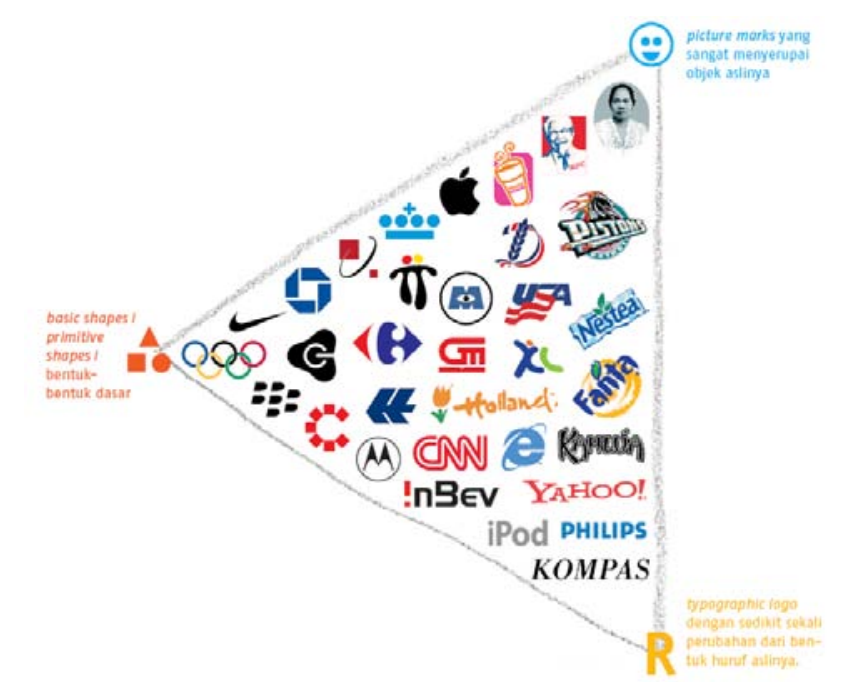

Gambar4. Klasifikasi logo berdasarkan kecenderungan bentuk dasarnya[6]

Tahap 3 : Konsep Desain Logo Dan Sistem Identitas Visual Fokus studi pada unit-3 ini adalah perumusan konsep dan kriteria desain logo dan system identitas yang akan dikembangkan pada tahap berikutnya. Ruang lingkup studi pada unit ini meliputi: Konsep desain (concept), Kriteria desain (design criteria) dan konsep penerapan logo \& system identitas pada media (media implementation planning). Luaran dari tahap ini adalahkonsep perencanaan desain logo dan system identitas visual serta rencana aplikasinya secara terintegrasi dalam berbagai media sesuai dengan programnya. Tujuan utama dari tahap ini adalah agar mahasiswa mampu merumuskan konsep desain logo dan rencana aplikasinya sebagai solusi untuk menjawab permasalahan identitas visual sesuaiprogramkorporatnya.

\section{Tahap 4 : Pengembangan Desain Logo}

Fokus studi pada tahap-4 ini adalah eksplorasi ide dan pengembangan gagasan desain logo dan identitas visual[8]. Tahapan proses desain yang dilakukan antara lain meliputi: Eksploriasi ide visual, sketsa ide (sketch), mengembangkandesain dan alternatif (alternative design and development), melakukan penyempurnaan (refinement) hingga membuat desain akhir (final design). Proses eksplorasi ide visual dapat dilakukan melalui berbagai macam metode, misalnya morphological matrix atau mind mapping[8]. Tujuan utama dari tahap ini agar mahasiswa mampu mengembangkan gagasan desain visual logo dan menerapkan prinsip-prinsip perancangan logo (Gambar 5)dan visual identity system dalam berbagai media secara terintegrasi.

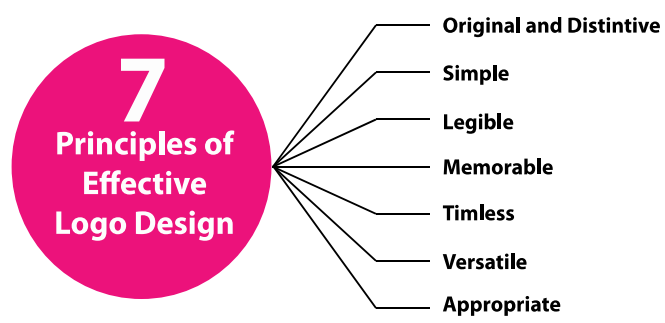

Gambar 5. Prinsip merancang logo yang efektif(Sumber: http://justcreative.com/2008/01/08/how-to-design-a-logo/)

\section{Penyederhanaan bentuk}

Stilasi atau penyederhanaan bentuk objek adalah bagian penting dalam desain visual. Karakter bentuk sebuah objek sangat beraneka ragam, sehingga perlu kepekaan untuk menangkap karakter khasnya. Dalam proses stilasi inidiperlukan kreativitas dan kepekaan visual desainernya dengan tujuan dapat menghasilkangambar baru yang masih dapat dikenali sebagai turunannya. Bentuk tidak perlu selalu naturalis, namun tetap tidak kehilangan karakter khas objek aslinya (Gambar 6).

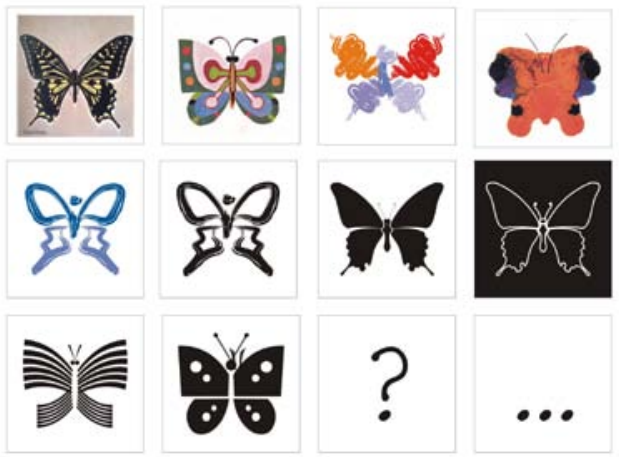

Gambar 6. Contoh eksplorasi ide dan stilasi gambar bentuk objek

\section{Tahap 5 : Penerapan logo dan sistem identitas}

Desain logo sebagai satu kesatuan system identitas tentu tidak berdiri sendiri, namun akan menempel pada media lainnya. Kesatuan system visual yang diterapkan secara konsisten dalam setiap media akan menjadi identitas khas bagi sebuah entitas yang diwakilinya. Namun demikian tetap dibutuhkan atribut-atribut lain untuk menjaga konsistensi penerapan logo pada berbagai media. Oleh karenanya, fokus studi pada unit ini menekankan pada pembuatan pedoman identitas visual (visual identity guideline) dan contoh desain aplikasinya pada berbagai media secara terintegrasi. Contoh materi presentasi akhir dapat pula dibuat dalam bentuk Mock up/model/dummy/prototip 2D maupun 3D.

Tujuan utama dari tahap ini adalah agar mahasiswa mampu membuat pedoman logo dan penerapan identitas visual dalam serangkaian media aplikasi secara terintegrasi. Kemudian mewujudkannya dalam bentuk karya presentasi akhir baik dalam bentuk Mock up, dummy, model atau prototype yang representative.

Pedoman system identitas visual atau sering disebut juga Visual Identity Guideline atau Graphic Standard Manual merupakan pegangan/ guidance bagi pihak perusahaan atau entitas dalam mempergunakan identitas visual yang dimilikinya. Tujuan utamanya adalah agar rancangan logo dan system identitas yang sudah dirancang tidak terjadi kesalahan dalam penerapannya. Pedoman system identitas visual ini secara umum harus mengakomodir hal-hal sebagai berikut.

- Logo primer, merupakan logo utama dengan berbagai unsurunsurnya yang akan dijadikan Logo utama umumnya digunakan dalam even formal.

- Logo sekunder,yakni visualisasi logo sekunder dan informasi yang terkait dengan unsur-unsurnya. Selain logo yang bersifat 
primer dan sekunder, tidak menutup kemungkinan jika dalam sebuah system identitas ada optionallogo yang digunakan untuk saat keperluan tertentu atau penerapan lain yang disarankan.

- Minimum clear space, merupakan panduan area minimal logo dengan objek-objek disekitarnya, sehingga visualisasi logo tampak lebih optimal.

- Signature size, adalah panduan ukuran logo, biasanya meliputi ukuran hingga skala terkecil yang disarankan.

- Signature color scheme, adalah panduan sistem warna yang digunakan termasuk alternative warna dalam kondisi tertentu, informasi kode warna untuk percetakan atau media online.

- Typography, merupakan panduan pemakaian Font/Typeface/type family tertentu yang digunakan, termasuk alternative huruf yang digunakan dalam media tertentu.

- Acceptable version, merupakancontoh-contoh penggunaan logo yang dibenarkan/disarankan.

- Unacceptable usage, merupakan contoh-contoh penerapan logo yang salah/ tidak dibenarkan.

- Design style/ application, umumnya berisi desain dan system grafisnya serta contohnya pada berbagai media yang diperlukan.

Berikut adalah contoh desain logo dan sistem grafis karyaHendricus Kusbiantoro. Iamemperlihatkan sebuah proses menarik yang dilakukan dalam pembuatan logo Ikatan Alumn TOP/ St. Aloysius dengan konsep "terbang tinggi, memberi arti”[3].

1. Konsep dasarnya berawal dari perjalanan hidup dirinya sebagai alumni TOP/ St. Aloysius tahun 1992. Impian menjadi kenyataan: lulus kuliah, alumnus beranjak dewasa, terbang landas! Terbang tinggi memenuhi ambisi, dari Bandung, Beijing, hingga Boston. Sampai di satu perhentian, burung-burung ini kembali teringat tempat mereka berasal saat mereka masih hijau dan mengayam tali persahabatan antar rantau. Kalimat Alumni TOP terbang.. terbang... terbang tinggi! Kini tidak lagi sekedar menggapai ambisi. Alumni St. Aloysius... terbang tinggi, memberi arti.”. ${ }^{1}$ menjadi kunci kata utama dalam konsep awal gagasannya.

2. Sketsa ide, merupakan proses brainstorming ide untuk menghasilkan berbagai kemungkinan bentuk visual logo yang diharapkan. Dalam tahap ini dilakukan sebaiknya dilakukan dengan menggunakan pinsil untuk menggambar cepat untuk menuangkan ide (Gambar 7).

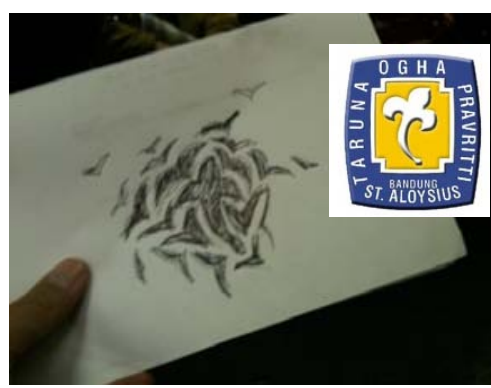

Gambar 7. Gambar sketsa ide(http://dgi.or.id/dgi-archive/2012logo-ikatan-alumnus-topst-aloysius)

3. Refinement (perbaikan), dilakukan dengan memperbaikinya dalam bentuk digital, kemudian dilakukan retouching kembali dengan berbagai kemungkinan permainan warna (Gambar 8).

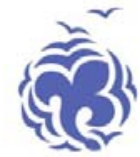

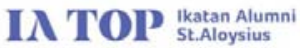

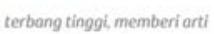

Gambar 8. Gambar logo hasil refinement digital(http://dgi.or.id/dgiarchive/2012-logo-ikatan-alumnus-topst-aloysius)

4. Finalisasi Logo, adalah tahap akhir perancangan logo terpilih yang siap diaplikasikan pada media-media (Gambar 9).

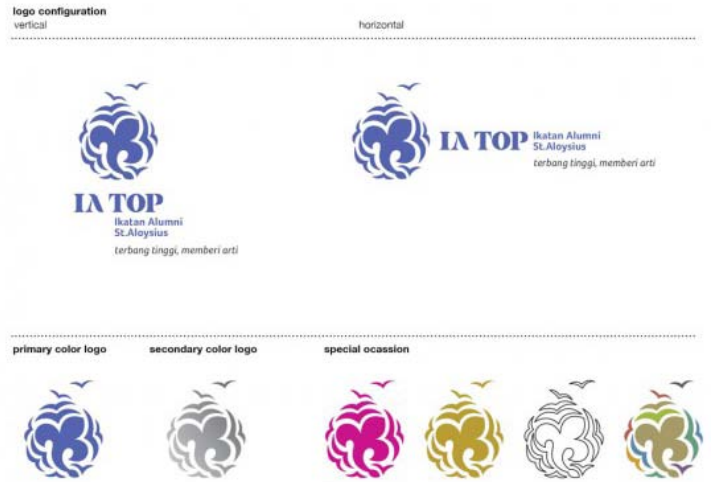

Gambar 9. Gambar final logo IA TOP-Ikatan Alumni St Aloysiushttp://dgi.or.id/dgi-archive/2012-logo-ikatanalumnus-topst-aloysius

5. Aplikasi logo, adalah tahap implementasi logo pada mediamedia yang relevan dengan kebutuhan. Sebagai contoh dalam hal ini "Ikatan Alumni Aloysius TOP" karya Hendricus Kusbiantoro (2012) diterapkan pada berbagai macam media sesuai dengan konsep pengembangan (Gambar 10, 11, 12 dan 14).
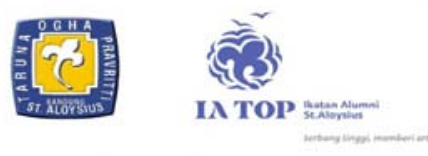

Gambar10. Contoh Logo IA TOP yang dikembangkan dari logo sekolah(http://dgi.or.id/dgi-archive/2012-logo-ikatan-alumnustopst-aloysius)

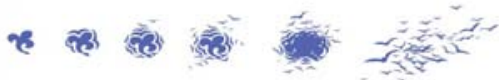

Gambar 11. Contoh pengembangan evolusi Logo/animatic experience(http://dgi.or.id/dgi-archive/2012-logo-ikatanalumnus-topst-aloysius) 
Sayatman, Nurina Orta Darmawati, Putri Dwitasari

Pengembangan Metode Desain Logo dan Sistem Grafis untuk Mendukung Pembelajaran Desain Komunikasi Visual

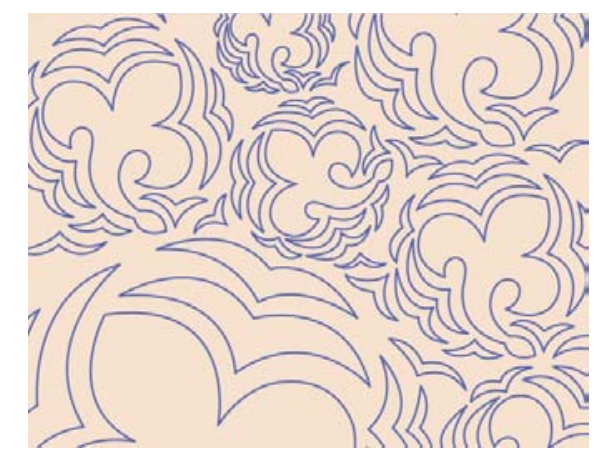

Gambar
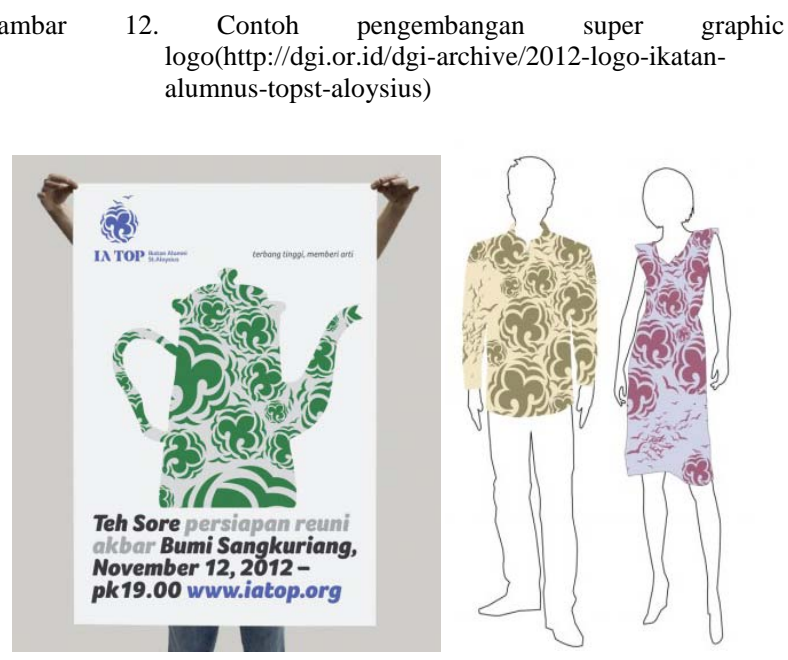

Gambar 13. Contoh pengembangan logo patern(http://dgi.or.id/dgiarchive/2012-logo-ikatan-alumnus-topst-aloysius)
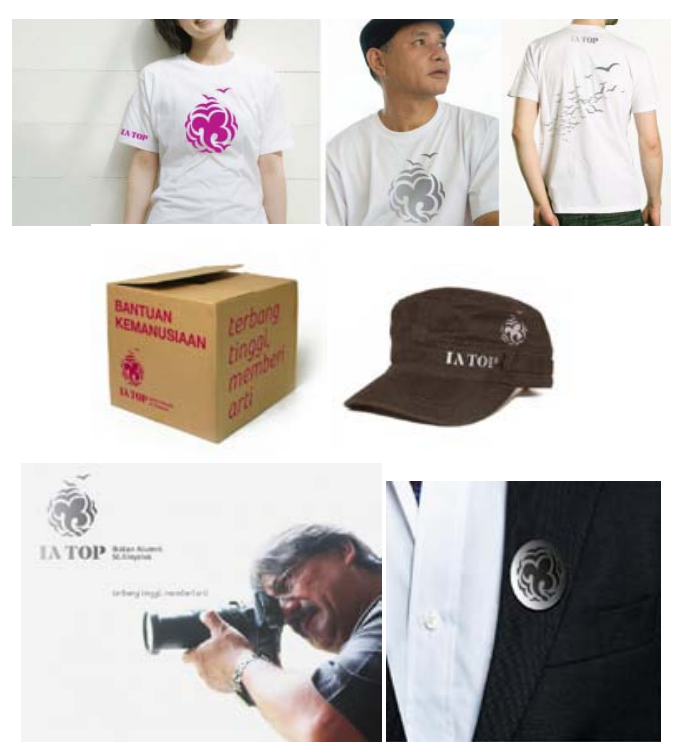

Gambar14. Contoh pengembangan logo pada berbagai media (http://dgi.or.id/dgi-archive/2012-logo-ikatan-alumnustopst-aloysius)

\section{KESIMPULAN}

1. Untuk mendesain logo dengan baik dan benar, diperlukan pemahaman yang komprehensif seorang desainer terhadap prinsip dasar, konsep dan metodenya.

2. Melalui cara penyampaian yang tepat, mahasiswa lebih mudah memahami prinsip-prinsip desain logo, sehingga mereka mampu merancang konsep dan implementasinya secara terintegrasi dalam berbagai media sebagai sebuah system grafis secara utuh.

Saran:

1. Meskipun demikian untuk perbaikan yang kontinyu yang dilengkapi dengan konten yang ter-update dan komprehensif dengan materi yang bisa menjelaskan setiap materi yang disajikan.

2. Perlu ditambahkan dengan contoh-contoh dan benchmark desain logo yang menarik dan up to date (kekinian), termasuk contoh karya hasil studi mahasiswa sendiri sebagai trigger bahwa karya-karya mahasiswa pun layak diangkat.

\section{DAFTAR PUSTAKA}

[1] Balmer, John, M.T \& Edmund R. Gray. (1998). ” Corporate Identity and Corporate Communications: Creating a strategic advantage," Corporate Communication.

[2] BrandHK Management Office (2003). Information Services Department Hong Kong Brand Guide.

[3] Henricus Kusbiantoro (2012). Logo "Ikatan Alumnus TOP/St. Aloysius".

[4] Morioka Adams (2004). Logo Design Workbook- A hands on Guide to Creating Logos.USA: Rockport Publishers, Inc.

[5] Murphy, John and Michael Rowe. How to Design Trademarks and Logos. Ohio : North Light Book, (1998).

[6] Rustan, Surianto, S.Sn.2009. Mendesain Logo. Jakarta: PT Gramedia Pustaka Utama

[7]

Sayatman,(2014).PengembanganDesainSistemIdentitasVi sualITSyangTerintegrasi dalamRangkaPenguatanBrandInstitusi.

[8] Pricken, M. (2002). Creative Advertising: Ideas and Techniques From the World's Best Campaigns, London: Thames \& Hudson. 